\title{
Multidimensional measurement of poverty and its spatio-temporal dynamics in China from the perspective of development geography
}

\author{
DONG Yin", "JIN Gui², DENG Xiangzheng ${ }^{3}$, WU Feng ${ }^{3}$
}

1. School of Public Administration, China University of Geosciences, Wuhan 430074, China;

2. School of Economics and Management, China University of Geosciences, Wuhan 430074, China;

3. Institute of Geographic Sciences and Natural Resources Research, CAS, Beijing 100101, China

\begin{abstract}
Exploring the spatio-temporal dynamics of poverty is important for research on sustainable poverty reduction in China. Based on the perspective of development geography, this paper proposes a panel vector autoregressive (PVAR) model that combines the human development approach with the global indicator framework for Sustainable Development Goals (SDGs) to identify the poverty-causing and the poverty-reducing factors in China. The aim is to measure the multidimensional poverty index (MPI) of China's provinces from 2007 to 2017, and use the exploratory spatio-temporal data analysis (ESTDA) method to reveal the characteristics of the spatio-temporal dynamics of multidimensional poverty. The results show the following: (1) The poverty-causing factors in China include the high social gross dependency ratio and crop-to-disaster ratio, and the poverty-reducing factors include the high per capita GDP, per capita social security expenditure, per capita public health expenditure, number of hospitals per 10,000 people, rate of participation in the new rural cooperative medical scheme, vegetation coverage, per capita education expenditure, number of universities, per capita research and development (R\&D) expenditure, and funding per capita for cultural undertakings. (2) From 2007 to 2017, provincial income poverty (IP), health poverty $(\mathrm{HP})$, cultural poverty $(\mathrm{CP})$, and multidimensional poverty have been significantly reduced in China, and the overall national poverty has dropped by $5.67 \%$ annually. there is a differentiation in poverty along different dimensions in certain provinces. (3) During the study period, the local spatial pattern of multidimensional poverty between provinces showed strong spatial dynamics, and a trend of increase from the eastern to the central and western regions was noted. The MPI among provinces exhibited a strong spatial dependence over time to form a pattern of decrease from northwestern and northeastern China to the surrounding areas. (4) The spatio-temporal networks of multidimensional poverty in adjacent provinces were mainly negatively correlated, with only Shaanxi and Henan, Shaanxi and Ningxia, Qinghai and
\end{abstract}

Received: 2020-08-16 Accepted: 2020-09-30

Funding: National Natural Science Foundation of China, No.71974070, No.41501593; National Key R\&D Project, No.2016YFA0602500; Humanities and Social Sciences Foundation of Ministry of Education of China, No.19YJCZH068

Author: Dong Yin (1992-), PhD Candidate, specialized in land resource evaluation and national land management. E-mail: dongy_simlab@163.com

*Corresponding author: Jin Gui, PhD and Professor, E-mail: jingui@igsnrr.ac.cn 
Gansu, Hubei and Anhui, Sichuan and Guizhou, and Hainan and Guangdong forming spatially strong cooperative poverty reduction relationships. These results have important reference value for the implementation of China's poverty alleviation strategy.

Keywords: development geography; multidimensional poverty; poverty measurement; spatio-temporal dynamics; collaborative poverty reduction

\section{Introduction}

Eliminating poverty is a major aim of human society. In recent years, China has implemented poverty alleviation strategies and formulated poverty reduction goals that have made important contributions to sustainable global development. The monitoring, evaluation, and dynamic tracking of collaborative poverty reduction mechanisms as well as studying their effects on alleviating regional poverty now form the focus of scientific research and national strategic decision making (Jin et al., 2019; Liao and Fei, 2019; Liu and Wang, 2019; Ding et al., 2020; Zhang et al., 2020). Early studies on poverty were conducted from the perspectives of economics (Ravallion et al., 1991; Dasgupta and Mäler, 1995; Haveman and Wolff, 2004), sociology (Harding, 2003; Rawal, 2008; Saunders et al., 2008), and politics (Sen, 1976; Arn, 1994). Since the development economist Amartya Sen proposed the capacities theory, the conventional assumptions about poverty based on the single-subject theory have been questioned in academic circles (Alkire and Foster, 2011; Haushofer and Fehr, 2014; Jin et al., 2018). Systematically determining poverty-reducing and poverty-causing factors to reveal such spatio-temporal characteristics of its dynamics as heterogeneity, diffusion, and convergence has become a popular subject of research in theoretical and practical work on poverty alleviation (Liu et al., 2017; Jin et al., 2020; Malerba, 2020). The multidimensional attributes, spatio-temporal correlation, and regional coordination of poverty provide fertile research grounds for geography, especially development geography. It integrates the research paradigms of development economics, the sociology of development, and economic geography, paying particular attention to regional developmental convergence in the process of improving the quality of human life (Glassman and Samatar, 1997; De Haan and Zoomers, 2003; Mawdsley, 2017). It enables sustainable research on poverty reduction to provide scientific support for policy making in the area.

Since the 1940s, development geography has begun analyzing the spatio-temporal differences in the economy, society, politics, and environment of countries or regions through research models of differentiation, diffusion, and convergence (Bird and Shepherd, 2003). With the problem of regional poverty and inequality caused by unbalanced development due to globalization, research on poverty in development geography has taken the lead in Western countries. From the perspective of the development of research topics related to poverty, the relevant studies have analyzed spatial differences in open systems with income growth as the core, forming a series of such theories as regional growth pole theory (Perroux, 1950), vicious circle of poverty theory (Nurkse, 1952), geographic dual economic structure theory (Myrdal and Sitohang, 1957), and polarization trickling-down-effect theory (Hirschman and Lindblom, 1962). Empirical cases examined subsequently by development geographers have verified the importance of such geographical features as factors determining comparative advantages in explanations of output volatility in underdeveloped regions (Malik and Tem- 
ple, 2009), examining the effect of poverty at the geographical scale (Kim et al., 2016), demonstrating the mechanism of interactions between barriers to labor mobility and geographical poverty traps (Guriev and Vakulenko, 2015), and discussing such spatial poverty-related issues as the effect of spatial heterogeneity on rural poverty reduction projects (Merfeld, 2019). The results have promoted poverty reduction and improving human well-being (Liverman, 2018). Development geography has also been widely recognized by decision makers and academics owing to its characteristics of spatial intervention. In recent years, the research on the geography of poverty in China has developed rapidly. According to the research model of pattern, process, and mechanism, and with the human-environment systems as theoretical basis, Information Technology and statistical methods have been applied to measure multidimensional poverty, depict its spatial patterns, and analyze its mechanism of occurrence (Ren et al., 2018; Wang et al., 2018; Wu et al., 2019). Some geographers have also constructed a multidimensional framework for the structural analysis of spatial poverty from the perspective of geographic capital and examined spatial poverty indicator systems (Liu et al., 2019). Research on sustainable poverty reduction in China remains inadequate, and has long lagged behind the national strategic demand for achieving a regional balance. The advantages of a theoretical analysis of poverty have not been exploited, and the spatial heterogeneity, diffusion, and integration of development geography have not been applied (Deng et al., 2020; Jin et al., 2020).

In light of the above, this paper proposes the human development approach and global indicator framework for Sustainable Development Goals (SDGs) based on the analysis paradigm of development geography, combined with the provincial panel data on China from 2007 to 2017, to identify poverty-reducing and poverty-causing factors in China. Based on this, a multidimensional poverty supervision evaluation indicator system that is compatible with China's current conditions is constructed. Through the evaluation of multidimensional poverty, the characteristics of spatio-temporal dynamics of poverty among regions are revealed, where this can provide a theoretical basis for targeted national poverty alleviation and prevention schemes. It can also provide a decision making reference for regional sustainable development.

\section{Materials and methods}

\subsection{Study area and data}

According to the Decision on Winning the Battle Against Poverty, by 2020, China's rural poor will be lifted out of poverty under the current standards (less than 2300 yuan a year). Current poverty alleviation work in the country has entered a critical stage. Relative poverty (i.e., compared with the average level, individuals cannot obtain all the resources they need in daily life) will remain challenge even after absolute poverty (i.e., individuals lack sufficient resources to meet their survival needs) has been eliminated. Sensitive indicators need to be formulated to monitor poverty, and a poverty alleviation policy is crucial for preventing people from falling back into poverty. This paper focuses on an analysis of key issues in poverty reduction research and national practice. The aim is to provide a reference for China's poverty alleviation strategy and prevent people from falling back into poverty by using 
using development geography.

Considering the availability of data, this study used all Chinese provinces (provinces, municipalities, and autonomous regions) as evaluation units (excluding Hong Kong, Macao, and Taiwan; Tibet was not considered owing to a lack of data). The data covered the population burden, natural disasters, economic development, social security, medical conditions, development of urbanization, and environmental background of the regions. Data on permanent residents, resident savings deposits, GDP, non-agricultural output value, social security expenditure, social gross dependency ratio, medical health expenditure, illiteracy rate, education expenditure, and number of universities were taken from the China Statistical Yearbook (2008-2018). Crop disaster data were taken from the China Rural Statistical Yearbook (2008-2018), data on the incidence of diseases, number of hospitals, rate of participation in new rural cooperative medical schemes, and health insurance of urban residents were drawn from the China Health and Family Planning Statistical Yearbook (2008-2018), vegetation coverage data were taken from the China Statistical Yearbook on Environment (2008-2018), R\&D funding data are from the China Statistical Yearbook on Science and Technology (2008-2018), data on funding for mass cultural undertakings were from the Statistical Yearbook of Chinese Cultural Relics (2008-2018), and the administrative boundaries of the provinces (municipalities and autonomous regions) were determined from the 1:4,000,000 National Fundamental Geographic Information Database (https:// www.resdc. $\mathrm{cn})$. The data were further processed into provincial panel datasets for research.

\subsection{Methodology}

\subsubsection{Identifying poverty-sensitive factors}

(1) Panel vector autoregressive (PVAR) model. Compared with the time series vector autoregressive (VAR) model, the PVAR relaxes the requirement on the length of the time series of data. It integrates the characteristics of individual heterogeneity in the panel data model with those of variable interaction in the VAR, which not only solves the endogenous problem, but also reflects the dynamic response-related relationship between variables (Love and Zicchino, 2006; Charfeddine and Kahia, 2019; Dong et al., 2020). The PVAR model is as follows:

$$
\delta_{i, t}=\lambda_{0}+\sum_{j=1}^{k} \lambda_{j} \delta_{i, t-j}+\mu_{i}+o_{i}+\varepsilon_{i, t}
$$

where $\delta_{i, t}$ is a matrix of endogenous variables, $\delta_{i, t-j}$ is a matrix of the explanatory variables, $\lambda_{0}$ and $\lambda_{j}$ are the coefficient matrices of the lag term, $\mu_{i}$ is the fixed effect variable of the difference in poverty between provinces, $O_{i}$ is the time-fixed effect term, and $\varepsilon_{i, t}$ is a stochastic disturbance term.

(2) Characteristic indicators and measurement indicators. The Human Development Report has formulated a theoretical paradigm for the human development approach and a global indicator framework for SDGs. It emphasizes that the focus of assessing development is the expansion and promotion of the national capacity. Poverty not only refers to economic poverty, but also includes a deterioration in health and a lack of education (Alkire, 2002; Rodríguez-Pose and Hardy, 2015; Jin et al., 2020), generally characterized by three indicators: per capita annual savings, rate of disease incidence, and illiteracy rate. However, these 
characteristic indicators cannot comprehensively describe the characteristics of poverty, or be used for dynamic monitoring and evaluation. Developing a way to identify poverty-reducing and poverty-causing factors in China from the three dimensions of income poverty (IP), health poverty (HP), and cultural poverty (CP), and constructing an indicator system for poverty monitoring and assessment are key issues that need to be addressed in theoretical and practical research on sustainable poverty reduction. Development geography is based on practical problems in the selection of indicators for measuring poverty, livelihood, and development convergence, where this can provide a new perspective on measuring poverty. Based on this, this paper uses per capita annual savings, rate of disease incidence, and illiteracy rate as characteristic indicators of the IP, HP, and CP, respectively. Combined with recent findings in research on poverty and statistical data in China, and by referring to the indicator systems proposed in the research (Ogutu and Qaim, 2019; Li et al., 2020; Yang et al., 2020; Guo et al., 2020), a candidate set of poverty assessment indicators (Table 1) is constructed. Note that compared with the traditional diagnosis of regional poverty, which pays more attention to such factors as location and resource endowment, this paper focuses on factors with high plasticity, such as the economic environment, social capital, and public facilities. The raw values of the indicators in Table 1 were normalized by logarithmic differences.

Table 1 The candidate set of poverty measurement indicators

\begin{tabular}{|c|c|c|c|}
\hline Dimension & Indicator & Meaning & Symbol \\
\hline \multirow{6}{*}{$\begin{array}{l}\text { Income } \\
\text { poverty A }\end{array}$} & $\begin{array}{l}\mathrm{A}_{0} \text { Per capita annual savings (yuan per } \\
\text { person) }\end{array}$ & Represents income poverty & $\ln P S D$ \\
\hline & $\mathrm{A}_{1}$ Per capita GDP (yuan per person) & $\begin{array}{l}\text { Reflects the level of regional economic } \\
\text { development }\end{array}$ & $\ln P G D P$ \\
\hline & $\begin{array}{l}\mathrm{A}_{2} \text { Proportion of non-agricultural industries } \\
(\%)\end{array}$ & $\begin{array}{l}\text { Reflects the regional industrial structure and } \\
\text { employment structure }\end{array}$ & $\ln I S$ \\
\hline & $\begin{array}{l}\mathrm{A}_{3} \text { Per capita social security expenditure } \\
\text { (yuan per person) }\end{array}$ & $\begin{array}{l}\text { Reflects the level of social security treatment } \\
\text { for residents }\end{array}$ & $\ln P S S E$ \\
\hline & $\mathrm{A}_{4}$ Social gross dependency ratio $(\%)$ & Reflects the burden on the working-age population & $\ln G D R$ \\
\hline & $\mathrm{A}_{5}$ Crop-to-disaster ratio (\%) & $\begin{array}{l}\text { Reflects the probability and vulnerability to } \\
\text { natural disasters }\end{array}$ & $\ln F C A$ \\
\hline \multirow{6}{*}{$\begin{array}{l}\text { Healthy } \\
\text { poverty B }\end{array}$} & $\mathrm{B}_{0}$ Rate of disease incidence ( $\left./ / 00\right)$ & Represents health poverty & $\ln I D I$ \\
\hline & $\begin{array}{l}\mathrm{B}_{1} \text { Per capita public health expenditure } \\
\text { (yuan per person) }\end{array}$ & $\begin{array}{l}\text { Reflects the government's investment in public } \\
\text { health care }\end{array}$ & $\ln P P H E$ \\
\hline & $\begin{array}{l}\mathrm{B}_{2} \text { Number of hospitals per } 10,000 \text { people } \\
\text { (unit per } 10,000 \text { persons) }\end{array}$ & $\begin{array}{l}\text { Reflects accessibility to basic public health } \\
\text { services in the region }\end{array}$ & $\ln P H O S$ \\
\hline & $\begin{array}{l}\mathrm{B}_{3} \text { Rate of participation in new rural } \\
\text { cooperative medical scheme }(\%)\end{array}$ & Reflects the level of rural medical coverage & $\ln N C M S$ \\
\hline & $\begin{array}{l}B_{4} \text { Health insurance coverage rate of urban } \\
\text { residents }(\%)\end{array}$ & $\begin{array}{l}\text { Reflects the coverage of basic medical care } \\
\text { services for residents }\end{array}$ & $\ln U H I$ \\
\hline & $\mathrm{B}_{5}$ Vegetation coverage $(\%)$ & Reflects the quality of the regional environment & $\ln F C R$ \\
\hline \multirow{6}{*}{$\begin{array}{l}\text { Cultural } \\
\text { poverty C }\end{array}$} & $\mathrm{C}_{0}$ Illiteracy rate $(\%)$ & Represents cultural poverty & $\ln I R$ \\
\hline & $\begin{array}{l}\mathrm{C}_{1} \text { Per capita education expenditure (yuan } \\
\text { per person) }\end{array}$ & $\begin{array}{l}\text { Reflects the intensity of financial investment in } \\
\text { public education }\end{array}$ & $\ln P E F$ \\
\hline & $\mathrm{C}_{2}$ Number of universities (unit) & Reflects the level of higher education & $\ln H E D U$ \\
\hline & $\mathrm{C}_{3}$ Student-teacher ratio (\%) & $\begin{array}{l}\text { Reflects the regional educational human resource } \\
\text { allocation }\end{array}$ & $\ln S T R$ \\
\hline & $\begin{array}{l}\mathrm{C}_{4} \text { Per capita research and development } \\
\text { (R\&D) expenditure (yuan per person) }\end{array}$ & $\begin{array}{l}\text { Reflects the intensity of investment in regional } \\
\text { scientific and technological financial resources }\end{array}$ & $\ln P R D$ \\
\hline & $\begin{array}{l}\mathrm{C}_{5} \text { Funding per capita for cultural } \\
\text { undertakings (yuan per person) }\end{array}$ & $\begin{array}{l}\text { Reflects the level of public cultural services for } \\
\text { the mass }\end{array}$ & $\ln P M C E$ \\
\hline
\end{tabular}




\subsubsection{Poverty measure}

To facilitate a comparative analysis of the status of poverty of the evaluation units, this paper uses the polyhedron method and quadrilateral chart method to measure multidimensional poverty and single-dimensional poverty, respectively (Xu et al., 2018).

(1) Multidimensional poverty index (MPI). The measurement of multidimensional poverty relies on a comprehensive integration method of multi-factors and multi-indicators. The polyhedron method is a method for calculating comprehensive index proposed in recent years. Compared with other methods, it is more flexible in calculation and beneficial to graphic expression. In this paper, the volume of polyhedron is the MPI, in which the straight line between the origin and each vertex is the evaluation indicator, and its length is the normalized value of the indicator. Due to differences in the importance of the dimensions and indicators in the evaluation system, the attribute weights of different indicators are considered when calculating the poverty index to ensure the accuracy of the results. The principle of calculation of the MPI is as follows:

$$
M P I_{-V}=\frac{1}{6} \sin \alpha\left(w_{B} \times a_{B} \times w_{C} \times a_{C}+\ldots+w_{D} \times a_{D} \times w_{B} \times a_{B}\right) \times\left(w_{A} \times a_{A}+w_{E} \times a_{E}\right)
$$

where $a_{A}-a_{E}$ are the standardized values of all indicators, $w_{A}-w_{E}$ represent the weight of each indicator, and $\alpha$ is the angle between two adjacent indicators.

(2) Single-dimensional poverty index measure. As relatively few indicators are involved, the polyhedron method is used to convert the calculated polyhedron volume into a polygonal area composed of multiple line segments. The formula is as follows:

$$
P I_{-A}=\frac{1}{2} \sin \alpha\left(w_{A} \times a_{A} \times w_{B} \times a_{B}+\ldots+w_{D} \times a_{D} \times w_{A} \times a_{A}\right)
$$

where $P I_{-}$is the polygonal area formed by standardized values of the single-dimensional poverty indicator, $\alpha_{A}-\alpha_{D}$ are the standardized values of all indicators, and $w_{A}-w_{D}$ are the weight of each indicator.

\subsubsection{Characteristics of spatio-temporal dynamics of multidimensional poverty}

Regionally coordinated poverty reduction and the balanced improvement of quality of life are important topics in research in development geography. The aim is to clarify the characteristics of spatio-temporal dynamics of poverty in the evaluation units considered here. This paper introduces the exploratory spatio-temporal data analysis (ESTDA) method (Rey, 2001) to reveal the spatio-temporal relations, patterns, and transitions of multidimensional poverty in China's provinces. It then depicts the characteristics of the spatial pattern of inter-provincial poverty and rules of evolution on the temporal scale.

(1) LISA time path. The temporal dimension is added to LISA analysis to reveal the dynamic track of the correlation characteristics of provincial multidimensional poverty in local space over time (Rey et al., 2011). The geometric features of the dynamic track in local space include the length and tortuosity. The relevant expressions are as follows:

$$
\Gamma_{i}=\frac{n \sum_{t=1}^{T-1} d\left(L_{i, t}, L_{i, t+1}\right)}{\sum_{i=1}^{n} \sum_{t=1}^{T-1} d\left(L_{i, t}, L_{i, t+1}\right)}, n=30
$$




$$
D_{i}=\frac{\sum_{t=1}^{T-1} d\left(L_{i, t}, L_{i, t+1}\right)}{d\left(L_{i, 1}, L_{t, T}\right)}
$$

where $\Gamma_{i}$ is length and $D_{i}$ is tortuosity, $d\left(L_{i, t}, L_{t, t+1}\right)$ represents the moving distance of province $i$ between years $t$ and $t+1$, and $L_{i, t}$ is the position of province $i$ on the Moran scatter plot in year $t$. The larger $\Gamma_{i}$ is, the longer the length is of the time path of the poverty index of province $i$, that is, the stronger the dynamics are of the local spatial structure. A smaller $\Gamma_{i}$ indicates a relatively stable local spatial structure, and $\Gamma_{i}>1$ indicates that the moving distance of province $i$ exceeds the national average distance, and is otherwise the opposite. A larger $D_{i}$ indicates that the dynamic path of the poverty index in province $i$ is more curved, showing a more dynamic local spatial dependence, while a smaller $D_{i}$ indicates a more stable direction of local spatial dependence. $D_{i}>1$ indicates that the dynamic track of province $i$ is more curved than the national average, and is otherwise the opposite.

(2) LISA spatio-temporal transition. The process of dynamic transition of the local spatial relationships among neighborhoods is further investigated, in four types. Type I indicates that no transition occurred in the given province and its neighbors with time, Type II refers to the transition of only the province, Type III refers to the transition of only the neighborhood, and Type IV refers to the transition of the province as well as its neighborhood. It is further divided into Type IV(1) and Type IV(2). The former indicates that the directions of transition of the province and its neighborhood are identical, and the latter indicates that these directions are opposite.

(3) Visualization of spatio-temporal dynamics. The advantage of the ESTDA framework is that it uses graph theory to express the changing complex geographical phenomena in an explicit way, which compensates for a lack of information relating to the spatio-temporal correlation characteristics in the coupling analysis of geographical spatio-temporal patterns (Ye and Carroll, 2011). The flow of the inter-provincial multidimensional poverty dynamic network can be visually expressed by calculating the correlation coefficient of covariance of the LISA's track of time movement in adjacent provinces.

\section{Results and analysis}

\subsection{Constructing poverty supervision evaluation indicator system}

\subsubsection{Identifying poverty-sensitive factors}

Based on the Akaike Information Criterion (AIC), Bayesian Information Criterion (BIC), and Hannan-Quinn Information Criterion (HQIC), we first determined the optimal lag order (i.e., the lag order can make the stochastic disturbance term satisfy the vector white noise process) of model estimation to be two lag periods. The relationship between the variables was then identified by the generalized method of moments (GMM) (Table 2). The direction of action and dynamic path between the variables and poverty in each dimension were analyzed by the impulse response function (IRF) (Figure 1). Finally, the poverty-causing and poverty-reducing factors at the provincial scale in China were identified. 
Table 2 Results of estimation of the relationship between indicator variables

\begin{tabular}{|c|c|c|c|c|c|}
\hline Variables & h_dlnPSD & Variables & h_dlnIDI & Variables & h_dlnIR \\
\hline Lag.h_dln $P S D$ & $\begin{array}{l}0.371^{* * *} \\
(-5.91)\end{array}$ & Lag.h_dln $I D I$ & $\begin{array}{l}-0.062 \\
(-0.57)\end{array}$ & Lag.h_dln $I R$ & $\begin{array}{c}-0.182^{* * *} \\
(-2.88)\end{array}$ \\
\hline Lag.h_dln $P G D P$ & $\begin{array}{l}0.109^{* * *} \\
(-3.25)\end{array}$ & Lag.h_dln $P P H E$ & $\begin{array}{c}-0.199^{* *} \\
(-2.54)\end{array}$ & Lag.h_dln $P E F$ & $\begin{array}{l}-0.138 \\
(-1.24)\end{array}$ \\
\hline Lag.h_dln $I S$ & $\begin{array}{c}0.234 \\
(-0.68)\end{array}$ & Lag.h_dlnPHOS & $\begin{array}{c}-0.363^{* *} \\
(-1.96)\end{array}$ & Lag.h_dln $H E D U$ & $\begin{array}{l}-0.394 \\
(-0.57)\end{array}$ \\
\hline Lag.h_dlnPSSE & $\begin{array}{l}0.096^{* * *} \\
(-4.00)\end{array}$ & Lag.h_dln $N C M S$ & $\begin{array}{c}-1.497^{* * *} \\
(-3.79)\end{array}$ & Lag.h_dlnSTR & $\begin{array}{c}0.060 \\
(-0.12)\end{array}$ \\
\hline Lag.h_dln $G D R$ & $\begin{array}{l}-0.027 \\
(-0.97)\end{array}$ & Lag.h_dln $U H I$ & $\begin{array}{c}0.056 \\
(-1.15)\end{array}$ & Lag.h_dln $P R D$ & $\begin{array}{c}-0.373^{* *} \\
(-2.08)\end{array}$ \\
\hline Lag.h_dln $F C A$ & $\begin{array}{c}-0.006^{* * *} \\
(-4.66)\end{array}$ & Lag.h_dln $F C R$ & $\begin{array}{c}-0.237^{* * *} \\
(-4.01)\end{array}$ & Lag.h_dln $P M C E$ & $\begin{array}{c}-0.197^{* * *} \\
(-3.06)\end{array}$ \\
\hline Lag2.h_dln $P S D$ & $\begin{array}{c}0.032 \\
(-0.97)\end{array}$ & Lag2.h_dln $I D I$ & $\begin{array}{l}-0.027 \\
(-0.37)\end{array}$ & Lag2.h_dln $I R$ & $\begin{array}{l}-0.029 \\
(-0.57)\end{array}$ \\
\hline Lag2.h_dln $P G D P$ & $\begin{array}{l}0.070^{* *} \\
(-2.12)\end{array}$ & Lag2.h_dln $P P H E$ & $\begin{array}{l}-0.058 \\
(-0.88)\end{array}$ & Lag2.h_dln $P E F$ & $\begin{array}{c}-0.231^{* *} \\
(-2.53)\end{array}$ \\
\hline Lag2.h_dln $I S$ & $\begin{array}{c}0.088 \\
(-0.37)\end{array}$ & Lag2.h_dlnPHOS & $\begin{array}{c}-0.334^{* *} \\
(-2.14)\end{array}$ & Lag2.h_dln $H E D U$ & $\begin{array}{c}-5.987^{* * *} \\
(-6.14)\end{array}$ \\
\hline Lag2.h_dln $P S S E$ & $\begin{array}{c}0.019 \\
(-1.15)\end{array}$ & Lag2.h_dln $N C M S$ & $\begin{array}{c}0.620 \\
(-1.02)\end{array}$ & Lag2.h_dlnSTR & $\begin{array}{c}0.084 \\
(-0.30)\end{array}$ \\
\hline Lag2.h_dln $G D R$ & $\begin{array}{c}-0.071^{* * * *} \\
(-2.87)\end{array}$ & Lag2.h_dln $U H I$ & $\begin{array}{l}-0.039 \\
(-1.07)\end{array}$ & Lag2.h_dln $P R D$ & $\begin{array}{l}-0.094 \\
(-0.86)\end{array}$ \\
\hline Lag2.h_dln $F C A$ & $\begin{array}{c}-0.005^{* * *} \\
(-4.34) \\
\end{array}$ & Lag2.h_dln $F C R$ & $\begin{array}{c}0.051 \\
(-0.49) \\
\end{array}$ & Lag2.h_dln $P M C E$ & $\begin{array}{l}-0.056 \\
(-1.23) \\
\end{array}$ \\
\hline
\end{tabular}

Notes: Lag. is first-period lag and Lag2. is second-period lags; in brackets are the $t$-test values, $* * *, * *$, and * indicating significant at levels of $1 \%, 5 \%$, and $10 \%$, respectively.

An analysis of Table 2 and Figure 1 shows that the second-period lags of the social gross dependency ratio and crop-to-disaster ratio had negative effects on the per capita annual savings at a significance of $1 \%$. It also exhibited a stepwise decreasing cumulative effect, which is a typical poverty-causing factor. The first-period lag of the per capita GDP and per capita social security expenditure in the IP indicators had a significant positive driving effect on the per capita annual savings, and both are poverty-reducing factors. From the overall effect of the trend of change, the first- or second-period lags of the per capita public health expenditure, number of hospitals per 10,000 people, rate of participation in new rural cooperative medical scheme, vegetation coverage in the HP indicators, per capita education expenditure, number of universities, per capita $R \& D$ expenditure, funding per capita for cultural undertakings in the CP indicators had significant negative and restrictive effects on the rate of disease incidence and illiteracy rate, and were also poverty-reducing factors.

\subsubsection{Poverty supervision and evaluation indicator system}

To further reveal the impact of various indicators on different dimensions of poverty, equal-weighted variance decomposition was carried out to assess the impact of each indicator. Figures $2 \mathrm{a}, \mathrm{b}$, and $\mathrm{c}$ show that the main influence of fluctuations in the per capita annual savings, rate of disease incidence, and illiteracy rate was internal, and tended to weaken in the long run. The contributions of other variables to these factors increased year by year and gradually approached a steady state in the fifth period. A comprehensive comparison of the decomposition results of variance over the 10 periods shows that numerical changes in the latter six periods were slight compared with those in the preceding four periods. We thus used data on the fifth period to quantitatively analyze the effects of various indicators on poverty. The results (Figure $2 \mathrm{~d}$ ) show that the multidimensional poverty supervision and 


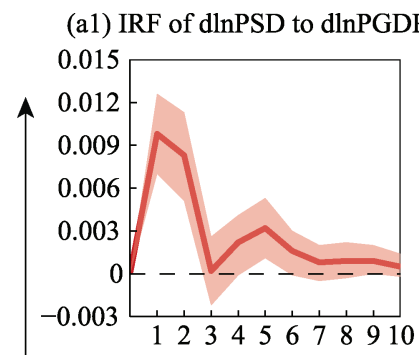

(b1) IRF of dlnIDI to dlnPPHE

(c1) IRF of dlnIR to dlnPEF

(a2) IRF of dlnPSD to dlnIS
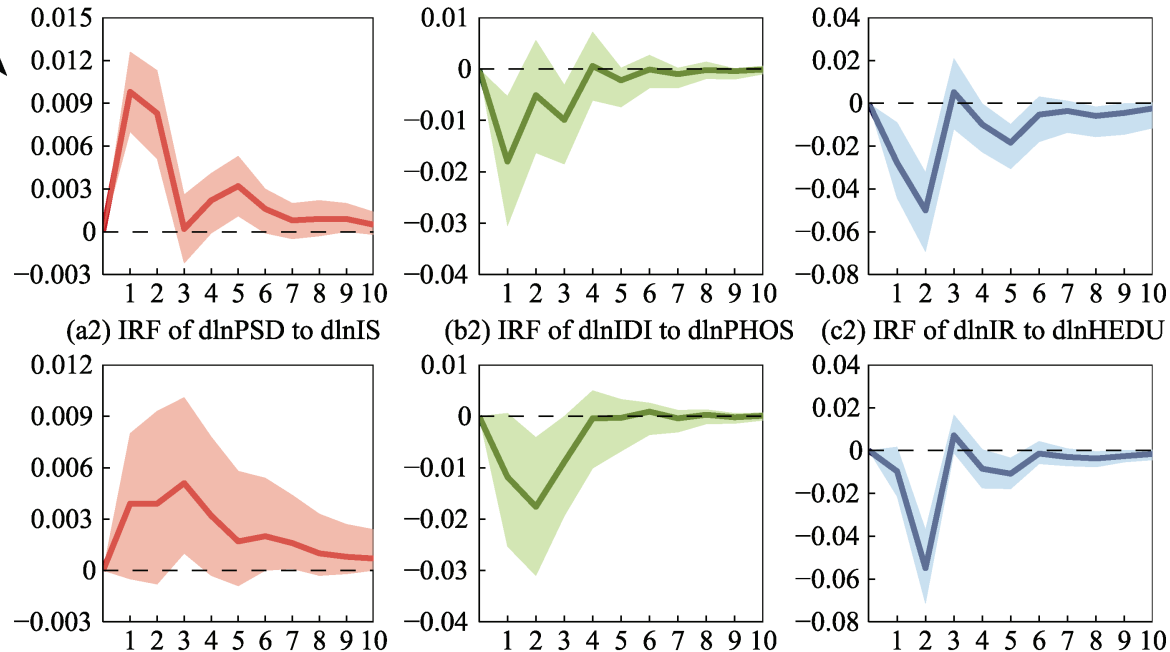

(b2) IRF of dlnIDI to dlnPHOS

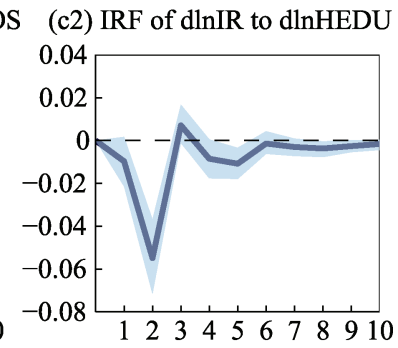

(a3) IRF of dlnPSD to dlnPSSE
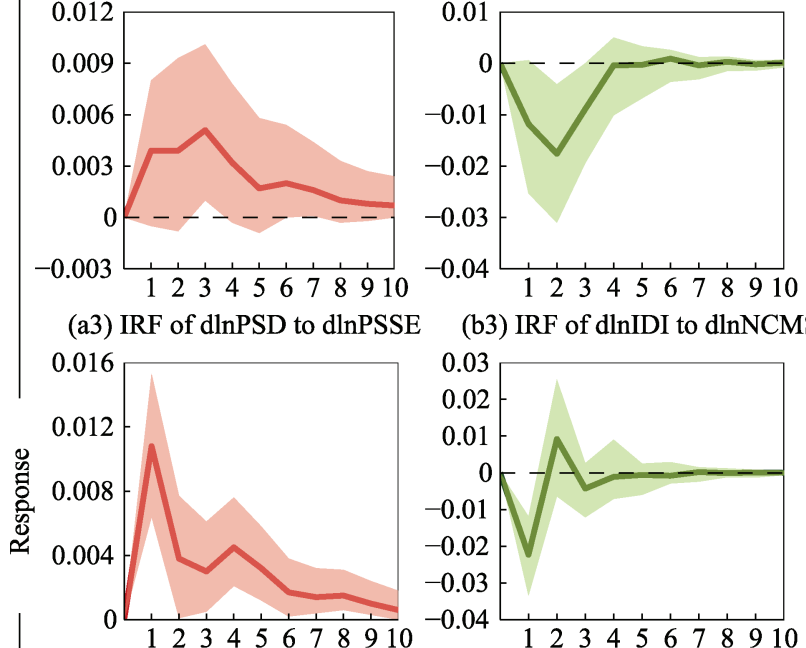

(c3) IRF of dlnIR to dlnSTR

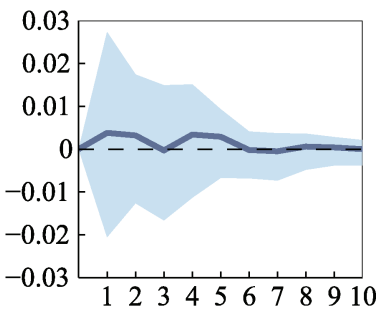

(a4) IRF of dlnPSD to dlnGDR

(b4) IRF of dlnIDI to dlnUHI

(c4) IRF of dlnIR to dlnPRD
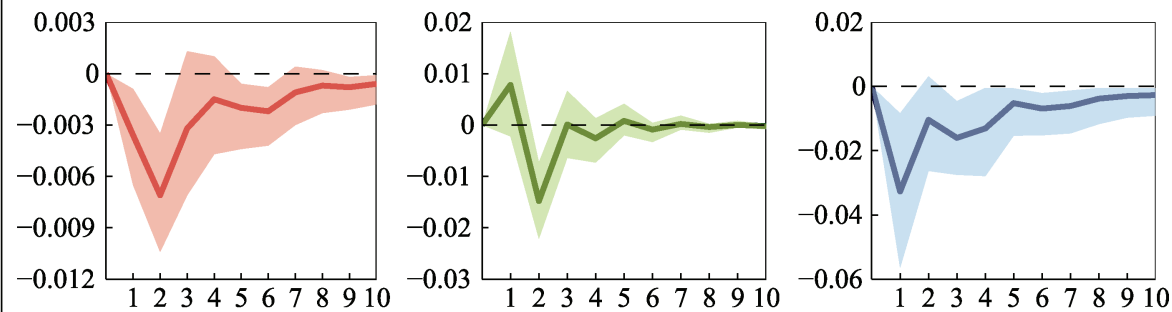

(a5) IRF of dlnPSD to dlnFCA

(b5) IRF of dlnIDI to dlnFCR

(c5) IRF of dlnIR to dlnPMCE
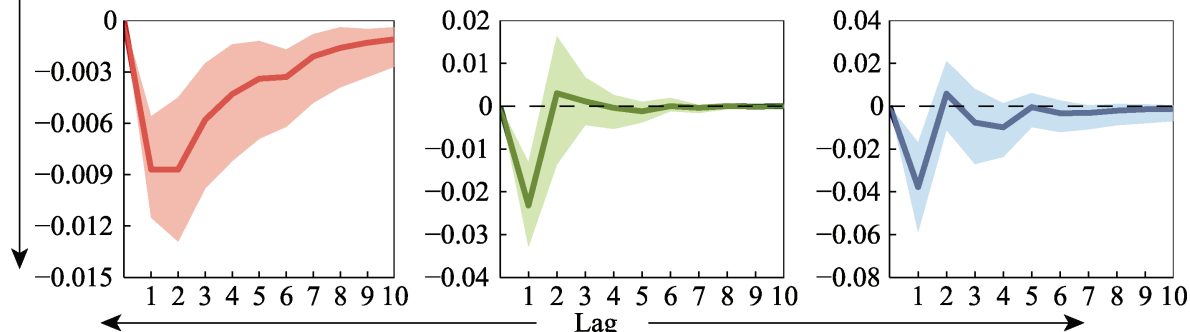

Figure 1 Results of impulse response of variables to characteristic indicators of multidimensional poverty

evaluation indicators at the provincial scale in China were determined according to the order of contribution of each variable from high to low, consisting of the 12 items of crop-to-disaster ratio, per capita GDP, per capita social security expenditure, per capita education expenditure, number of universities, social gross dependency ratio, rate of participation in the new rural cooperative medical scheme, vegetation coverage, number of hospitals 
per 10,000 people, per capita public health expenditure, per capita R\&D expenditure, and funding per capita for cultural undertakings. These indicators can provide the basis for multidimensional poverty dynamic supervision and comprehensive measurement at the provincial scale in China.

(a) Variance decomposition of IP

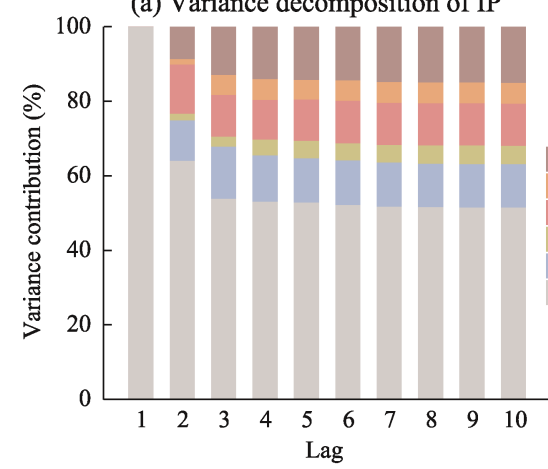

(c) Variance decomposition of CP

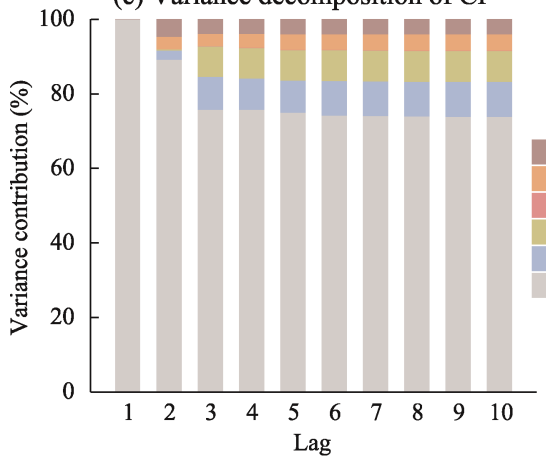

(b) Variance decomposition of HP

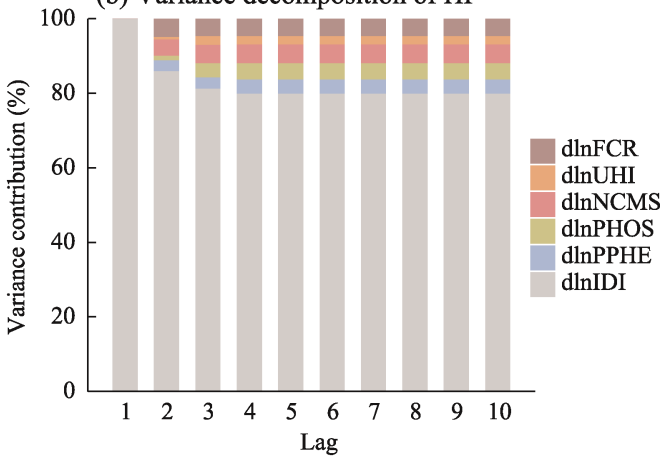

(d) Variance decomposition of MPI to other variables

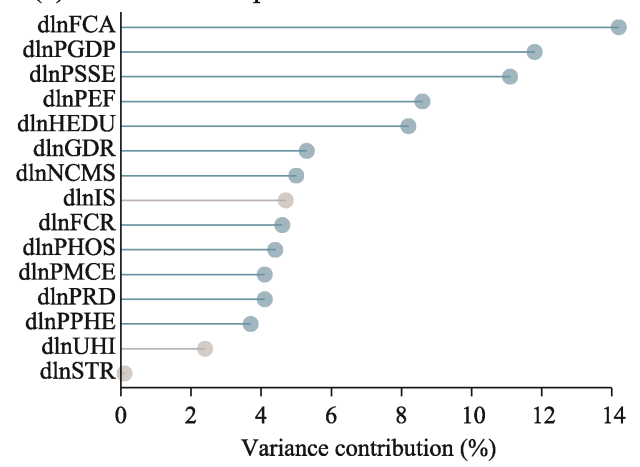

Figure 2 Results of variance decomposition of the poverty indicators

\subsection{Results of multidimensional poverty measurement}

\subsubsection{Results of single-dimensional poverty measurement}

The weights of the poverty indicators were determined by the analytic hierarchy process (AHP) and the entropy value method (EVM), where these methods were adapted to the results of variance decomposition. The provincial single-dimensional poverty indices for 2007, 2012, and 2017 were calculated by Formula (3) (Figure 3) and the spatio-temporal rule of evolution of the single-dimensional poverty index was analyzed.

In terms of time scale, China's IP decreased by 58.13\% from 2007 to 2017, showing a clear trend of decrease, with Henan, Qinghai, and Hebei showing a slower decline than the other provinces. The cumulative rates of decline of IP in the eastern, central, and western regions were $64.7 \%, 53.06 \%$, and $57.11 \%$, respectively, showing that the overall regional differences are gradually narrowing. The HP in China decreased by $55.18 \%$, with significant differences among the provinces. The declines in Beijing, Guizhou, Shanghai, Qinghai, and Chongqing were significantly higher than the national average, while those in Henan, Heilongjiang, Jilin, and Xinjiang showed relatively minor reductions. China's CP has gradu- 
ally decreased, with the overall poverty level declining by $50.64 \%$, where the average annual decline rates in the eastern, central, and western regions were $8.49 \%, 5.72 \%$, and $6.39 \%$, respectively. This was closely related to the nation's development of education, science and technology, and culture in the central and western regions in recent years, especially the construction of a mass cultural infrastructure. At the national level, the poverty index in different dimensions dropped significantly faster than in previous years after 2012. In general, in the process of implementing the targeted poverty alleviation strategy, the poverty reduction along all dimensions was remarkable given the various dimensions of poverty, but there is room for reductions in the HP and CP.

(a) 2007

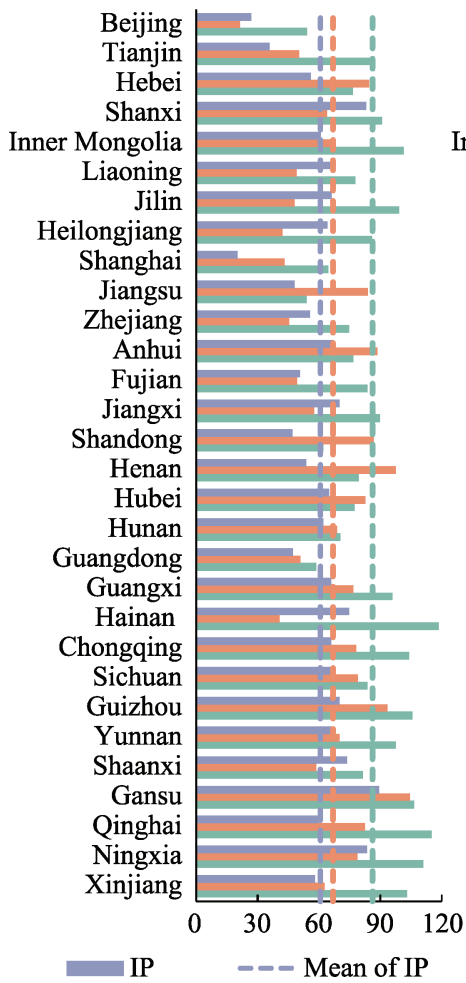

(b) 2012

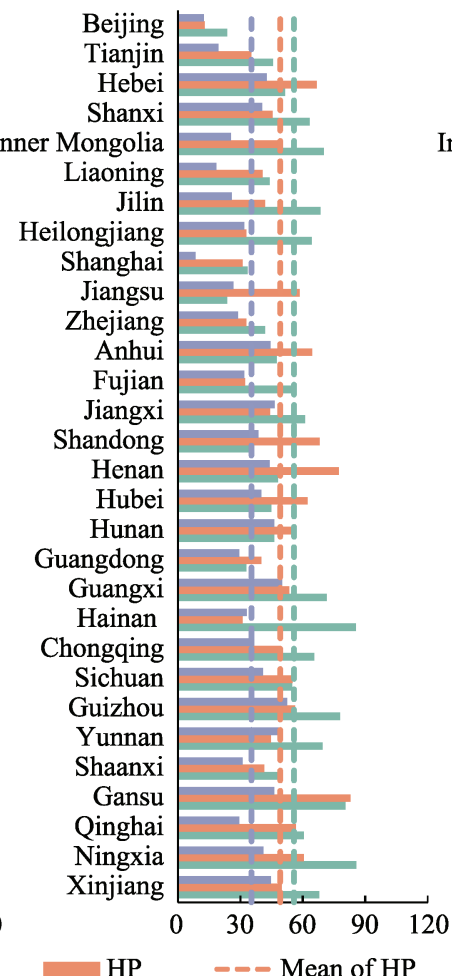

(c) 2017

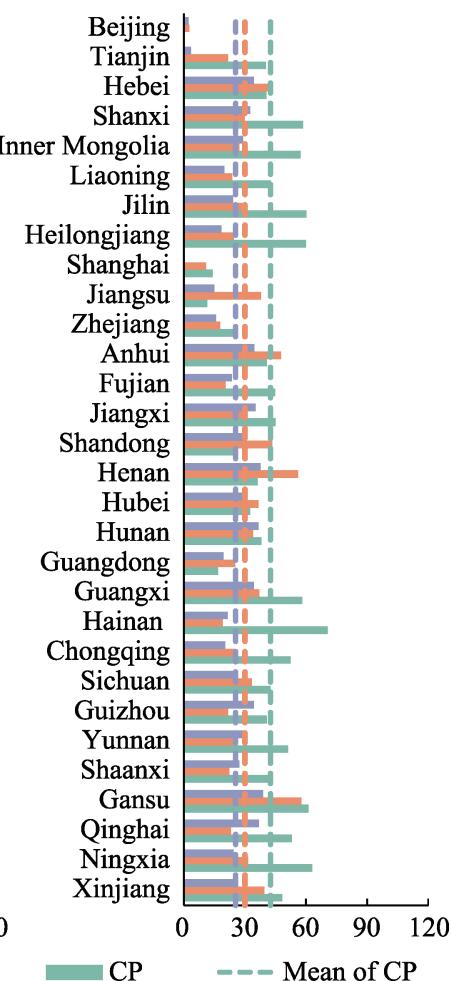

Figure 3 Results of measurement of provincial single-dimensional poverty in 2007, 2012, and 2017

In terms of the spatial pattern, the high values of IP were mainly concentrated in Gansu and Ningxia in northwest China, Guizhou, Guangxi, and Yunnan in southwest China, and Shanxi, Jiangxi, and Anhui in the central regions. These provinces have weak economic foundations and relatively poor natural resource endowment. They are located along the edge of China's economic growth space, and constitute regions where contiguous poor areas form in China. Areas with higher levels of HP are distributed in Shandong, Hebei, Henan, Anhui, Hubei, Gansu, Guizhou, and Ningxia. Most of these provinces are populous, or are located in the central and western mountainous areas, and their community health service capabilities are limited, where this affects preventive health services and the scope of disease treatment. The spatial pattern of CP shows that Hainan, Ningxia, Gansu, Inner Mongolia, Qinghai, Guangxi, and Guizhou have high levels of CP. These regions have problems, such 
as relatively little investment in education, unbalanced allocation of cultural and educational resources, and insufficient vitality in the development of public cultural industries, which have led to the relatively backward cultural and educational levels for the poor.

Important here are the significant differences among the three dimensions of poverty within some provinces. For example, the HP in Henan and Shandong, and the CP in Hainan, Jilin, and Inner Mongolia were significantly higher than the other two dimensions in these provinces. The imbalance in poverty has formed weak links for sustainable poverty reduction. Thus, balancing poverty along all dimensions should be the focus of poverty reduction in future policies implemented by the government.

\subsubsection{Results of comprehensive measurement of multidimensional poverty}

To better reflect the poverty-related situation in each province, China's provincial MPIs for 2007, 2012, and 2017 were calculated using Formula (2) (Figure 4). The MPI in the western provinces was the highest during the study period, followed by the central provinces, and was the lowest in the eastern provinces, showing a stepwise distribution that gradually increasing from east to west similar to the topography of the land. At the same time, the poverty gap between the western, and the eastern and central regions gradually narrowed. The trend of change in the of MPI showed that national multidimensional poverty decreased by $5.67 \%$ annually from 2007 to 2017 . In particular, poverty has decreased by $7.22 \%$ annually since the implementation of the targeted poverty alleviation strategy in 2012. In spite of this, China's multidimensional poverty still showed a significant overall imbalance and the spatial polarization of regional poverty. For example, poverty levels in Gansu, Guizhou, Ningxia, Henan, Guangxi, Yunnan, Shanxi, and Anhui were higher than the national average.

\subsection{Characteristics of spatio-temporal dynamics of multidimensional poverty}

3.3.1 Changes in time path of multidimensional poverty in local space

The LISA time path of provincial MPI during the study period (Figure 5a) shows that provinces with a time path greater than 1 accounted for $43.33 \%$, that is, the local pattern of multidimensional poverty obeyed a rule of evolution over
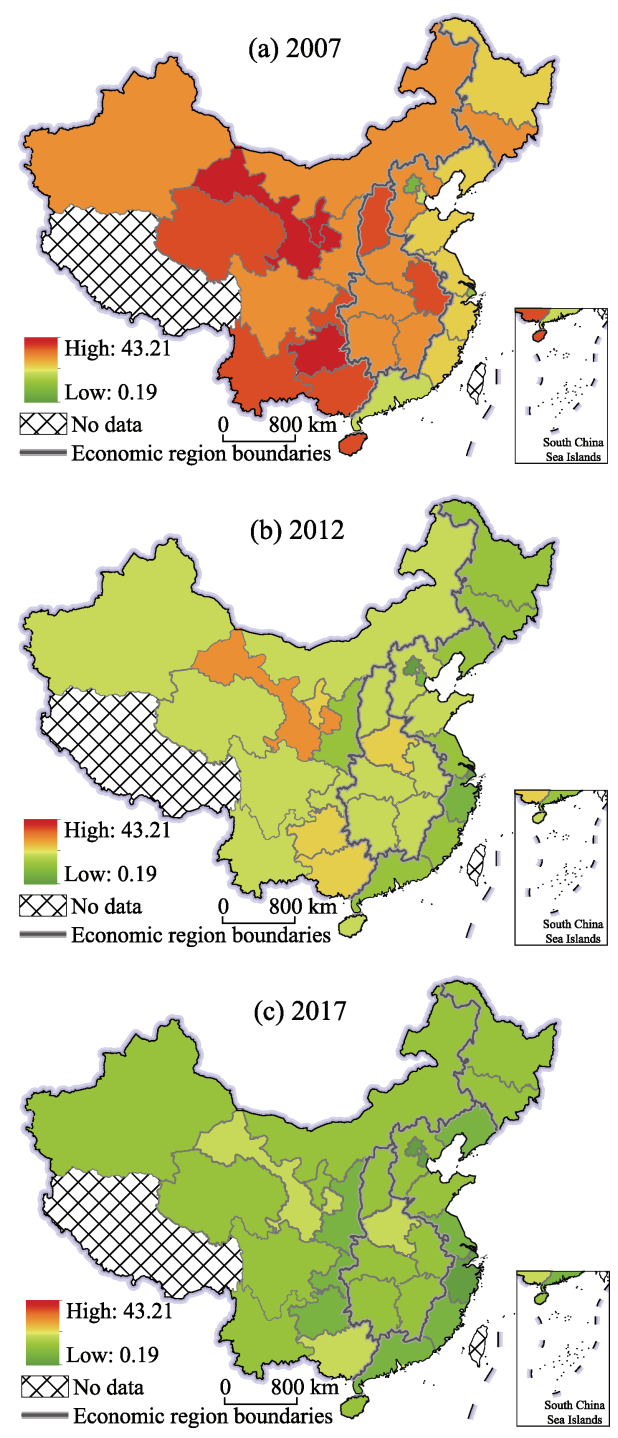

Figure 4 Results of comprehensive measurement of multidimensional poverty in China in 2007, 2012, and 2017 
time. The time path shows a trend of increase from the eastern to the central and western regions, where the lengths of Guizhou, Qinghai, and Xinjiang in the western regions were greater than 1.25 , which indicates that their local spatial structures were highly dynamic. Beijing, Shanghai, Tianjin, and Shandong in the eastern regions were provinces with relatively short time path movements, with lengths shorter than 0.8 . This is mainly because the eastern coastal provinces are economically developing well, have abundant natural resources, and have low absolute poverty levels, which constitutes a stable local spatial structure of poverty. Figure $5 \mathrm{~b}$ shows that tortuosity was higher than 1 in all areas, and the overall spatial distribution showed a trend of decrease from northwestern and northeastern China to the surroundings. This shows that the MPI in each province was heavily spatially dependent over time. Provinces with higher tortuosity included northeastern China, Hainan, and Qinghai, reflecting the clear dynamic transition and interaction between them and their neighborhood. Provinces with lower tortuosity were scattered at the intersection of central, northwestern, and southwestern China, and multidimensional poverty in them exhibited a stable, changing direction as well as spatial dependence.
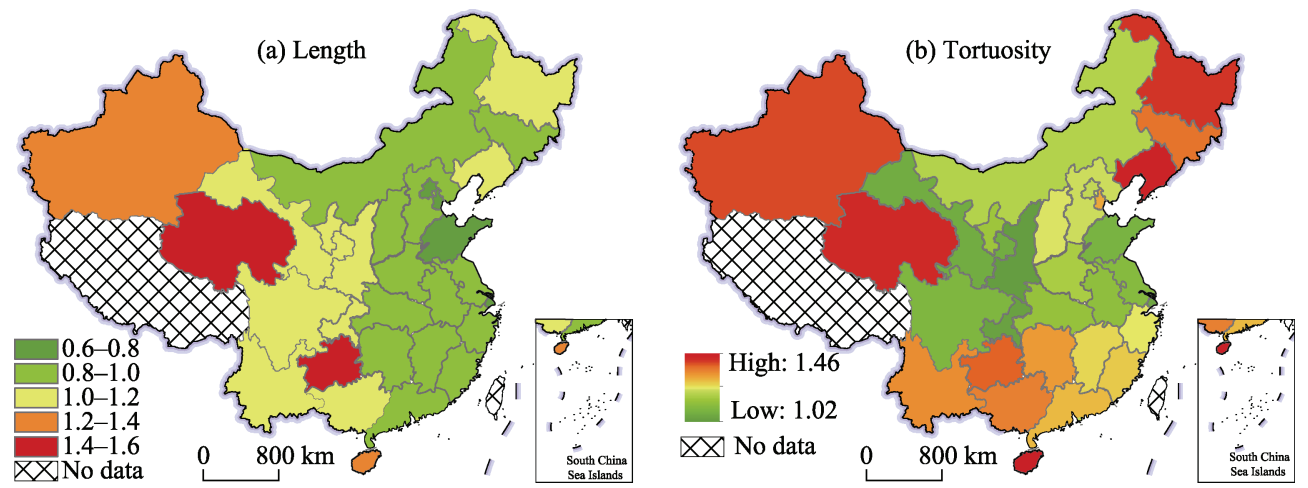

Figure 5 Spatial distribution of geometric features of the LISA time path in China

\subsubsection{Spatio-temporal transition of local space of multidimensional poverty}

We used spatio-temporal transition analysis to examine the transfer characteristics of types of local spatial associations in multidimensional poverty among provinces of China (Table 3). The proportions of provinces of the Type I transition over the three periods of 2007-2011, 2012-2017, and 2007-2017 were $83.33 \%, 80 \%$, and $73.33 \%$, respectively, indicating the path dependence of multidimensional poverty distribution in China's provinces. The spatial relative state of multidimensional poverty in the provinces improved after the implementation of the targeted poverty alleviation strategy in 2012, but it remains difficult to completely reverse the current inter-provincial poverty interaction in the short term. For Yunnan, Gansu, Qinghai, Ningxia, Xinjiang, and other provinces where the contiguous poor areas are concentrated, the stability of poverty makes them the key areas that restrict China's coordinated poverty reduction. From 2007 to 2017, the provinces with Type II transition accounted for $23.33 \%$, mainly distributed in the central and western regions, which indicated that the local spatial correlation structure of poverty in these regions was weaker than that in the eastern regions. During the study period, the number of provinces with Type III and Type IV 
transitions was only 1 and 0 , respectively. The proportion of provinces with four transition types indicates that the national poverty reduction strategy needs to further build a coordinated mechanism for poverty reduction between regions to promote high-quality poverty reduction in severely impoverished areas. In addition, note that the overall transition of Type II provinces rendered them key in driving the transition in China's multidimensional poverty, and more attention should be paid to poverty reduction policies.

Table 3 Spatio-temporal transition matrices of multidimensional poverty

\begin{tabular}{|c|c|c|c|c|c|}
\hline Period & & $\mathrm{HH}$ & LH & LL & HL \\
\hline \multirow{4}{*}{ 2007-2011 } & $\mathrm{HH}$ & $\begin{array}{l}\text { Type I (Shanxi, Henan, Hubei, } \\
\text { Guangxi, Chongqing, Sichuan, } \\
\text { Guizhou, Yunnan, Gansu, Qinghai, } \\
\text { Ningxia, Xinjiang) }\end{array}$ & $\begin{array}{l}\text { Type II (Inner } \\
\text { Mongolia, Shaanxi) }\end{array}$ & Type IV(1) & Type III \\
\hline & LH & Type II (Shandong, Hunan) & $\begin{array}{l}\text { Type I (Liaoning, } \\
\text { Guangdong) }\end{array}$ & $\begin{array}{l}\text { Type III } \\
\text { (Heilongjiang) }\end{array}$ & Type IV(2) \\
\hline & LL & Type IV(1) & Type III & $\begin{array}{l}\text { Type I (Beijing, } \\
\text { Tianjin, Jilin, } \\
\text { Shanghai, Jiangsu, } \\
\text { Zhejiang, Fujian) }\end{array}$ & Type II \\
\hline & $\mathrm{HL}$ & Type III & Type IV(2) & Type II & $\begin{array}{l}\text { Type I (Hebei, } \\
\text { Anhui, Jiangxi, } \\
\text { Hainan) }\end{array}$ \\
\hline \multirow{4}{*}{$2012-2017$} & $\mathrm{HH}$ & $\begin{array}{l}\text { Type I (Shanxi, Shandong, He- } \\
\text { nan, Hubei, Hunan, Sichuan, Yun- } \\
\text { nan, Gansu, Qinghai, Ningxia, } \\
\text { Xinjiang) }\end{array}$ & $\begin{array}{l}\text { Type II (Chongq- } \\
\text { ing, Guizhou) }\end{array}$ & Type IV(1) & $\begin{array}{l}\text { Type III (Gua- } \\
\text { ngxi) }\end{array}$ \\
\hline & LH & Type II (Inner Mongolia) & $\begin{array}{l}\text { Type I (Liaoning, } \\
\text { Guangdong, Shaan- } \\
\text { xi) }\end{array}$ & Type III & Type IV(2) \\
\hline & LL & Type IV(1) (Heilongjiang) & Type III & $\begin{array}{l}\text { Type I (Beijing, } \\
\text { Tianjin, Shanghai, } \\
\text { Jiangsu, Zhejiang, } \\
\text { Fujian) }\end{array}$ & Type II (Jilin) \\
\hline & $\mathrm{HL}$ & Type III & Type IV(2) & Type II & $\begin{array}{l}\text { Type I (Hebei, } \\
\text { Anhui, Jiangxi, } \\
\text { Hainan) }\end{array}$ \\
\hline \multirow{4}{*}{$2007-2017$} & $\mathrm{HH}$ & $\begin{array}{l}\text { Type I (Shanxi, Inner Mongolia, } \\
\text { Henan, Hubei, Sichuan, Yunnan, } \\
\text { Gansu, Qinghai, Ningxia, Xinjiang) }\end{array}$ & $\begin{array}{l}\text { Type II (Chongq- } \\
\text { ing, Guizhou, } \\
\text { Shaanxi) }\end{array}$ & Type IV(1) & $\begin{array}{l}\text { Type III (Gua- } \\
\text { ngxi) }\end{array}$ \\
\hline & LH & $\begin{array}{l}\text { Type II (Heilongjiang, Shandong, } \\
\text { Hunan) }\end{array}$ & $\begin{array}{l}\text { Type I (Liaoning, } \\
\text { Guangdong) }\end{array}$ & Type III & Type IV(2) \\
\hline & LL & Type IV(1) & Type III & $\begin{array}{l}\text { Type I (Beijing, } \\
\text { Tianjin, Shanghai, } \\
\text { Jiangsu, Zhejiang, } \\
\text { Fujian) }\end{array}$ & Type II (Jilin) \\
\hline & $\mathrm{HL}$ & Type III & Type IV(2) & Type II & $\begin{array}{l}\text { Type I (Hebei, } \\
\text { Anhui, Jiangxi, } \\
\text { Hainan) }\end{array}$ \\
\hline
\end{tabular}

\subsubsection{Spatio-temporal network analysis}

To better show the geographical essence behind the poverty visualization (Chen et al., 2018), this study shows the spatio-temporal network of multidimensional poverty dynamics in provinces neighboring one another (Figure 6). According to the pattern of the multidimen- 
sional poverty geographical network and topological networks of the provinces, 38 pairs were negatively correlated, accounting for $58.46 \%$, which indicates a certain spatio-temporal competition in the evolution of poverty between neighboring provinces. Of all negative correlations, $81.58 \%$ were weak, and were mainly concentrated in the northeastern and central provinces, and a few were distributed in the western regions. From the perspective of the theory and rules of development geography, the poverty phenomenon and patterns of poverty reduction between neighboring provinces conformed to their evolutions in terms of differentiation, diffusion, and convergence. The imbalance in geographical capital space has increased competition between provinces for poverty reduction and limited the convergence of regional development. The strong negative correlations between Beijing and Tianjin, Inner Mongolia and Liaoning, Shanghai and Zhejiang, Sichuan and Gansu, and Xinjiang and Qinghai reveal the uncoordinated features of poverty reduction among provinces. There may be some regional closure when implementing poverty reduction measures in each province, which is reflected in the relatively weak effect of poverty reduction in regions around the administrative boundaries. These regions should pay more attention to the role of collaborative poverty reduction. On the contrary, Shaanxi and Henan, Qinghai and Gansu, Hubei and Anhui, Sichuan and Guizhou, and Hainan and Guangdong formed strong coordination zones, showing positive spatial dynamics. The characteristics of multidimensional poverty in these provinces were similar, and the trend of regional concentration of multidimensional poverty appeared. These regions have implemented coordinated poverty reduction programs, such as the National Poverty Alleviation Policy for the Dabie Mountain Contiguous Poor Areas, but can further cooperate for poverty reduction.

(a) Geographical networks

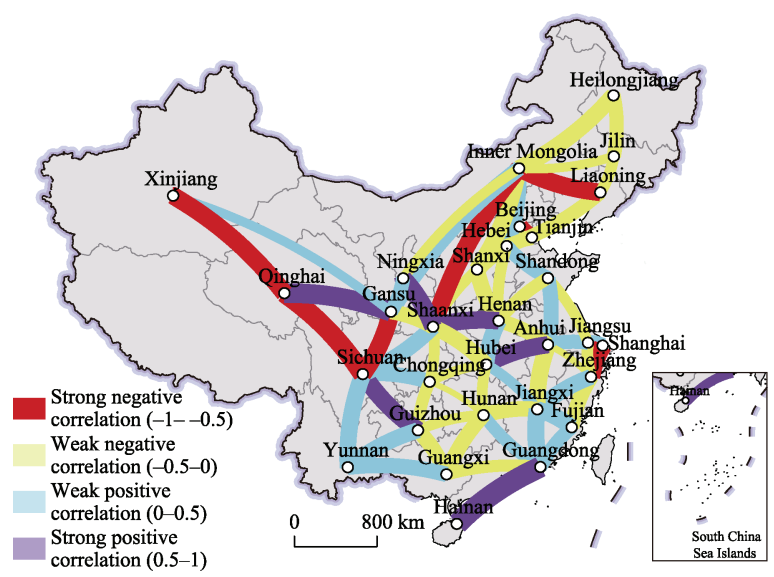

(b) Topological networks

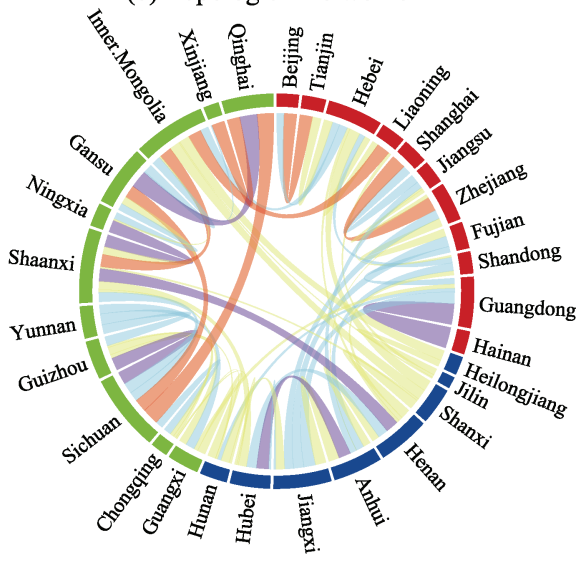

Figure 6 Spatio-temporal network of multidimensional poverty dynamics among provinces in China

\section{Conclusions and discussion}

\subsection{Conclusions}

Based on an analytical model of the differentiation, diffusion, and convergence of develop- 
ment geography, in this paper, we identified factors affecting poverty in China from the perspectives of human development approach and the global indicator framework for SDGs, and constructed a multidimensional poverty supervision evaluation indicator system to explore the characteristics of spatio-temporal dynamics of multidimensional poverty. The results showed the following:

(1) According to GMM and IRF analyses, we determined the direction, extent, and path of the influential factors on poverty in China, and identified the poverty-reducing and poverty-causing indicators. Except the proportion of non-agricultural industries, health insurance coverage rate of urban residents, and student-teacher ratio, other indicators are significantly related to poverty. The social gross dependency ratio and crop-to-disaster ratio were identified as poverty-causing factors, and the other 10 indicators, including the per capita GDP, rate of participation in the new rural cooperative medical scheme, and per capita education expenditure, were poverty-reducing factors.

(2) During the study period, the IP, HP, CP, and MPI showed a significant downward trend, and the overall difference in poverty among the provinces was shown to have gradually narrowed. The three dimensions of poverty in some provinces were characterized by non-convergence, and the internal polarization of multidimensional poverty was clear. The state of multidimensional poverty in China shows the spatio-temporal imbalance between provinces, which led to a coupling relationship with the patterns of geographical differentiation of the regional economic space.

(3) The local spatial pattern of multidimensional poverty among provinces in China shows a differentiation. The local spatial structure of the MPI in western provinces was strongly dynamic, and the spatial status of multidimensional poverty in various provinces is difficult to change in the short term. In addition, during the evolution of multidimensional poverty, regions in northeastern China, and the central and western regions showed a negative correlation. Shaanxi and Henan, Shaanxi and Ningxia, Qinghai and Gansu, Hubei and Anhui, Sichuan and Guizhou, and Hainan and Guangdong constituted growth areas that had engaged in extensive coordination. Coordinated inter-provincial poverty reduction should be the focus of sustainable poverty reduction in the future.

\subsection{Discussion}

In 2020, the long-standing primary absolute poverty in China will come to an end, and the battle against poverty reduction will enter a new stage. Relative poverty will become an important challenge in China's post-poverty alleviation era, and imposes new demands on its anti-poverty program. In this new period, the focus of development-oriented poverty alleviation work will shift from solving the problem of food and clothing, to preventing the risk of a return to poverty. Due to the prevalence of regional differences, group differences, and differences in demand in terms of vulnerability to poverty among communities, the pattern of regional poverty reduction, process of coupling interaction and hierarchical transmission mechanism under different spatio-temporal scales are characterized by complexity and nonlinear dynamic evolution. Therefore, going beyond the current theoretical paradigm of poverty reduction, and exploring the heterogeneous 
characteristics, state of diffusion, and mode of convergence of sustainable livelihoods and development in underdeveloped areas will become the new focus and direction of research in this area.

Poverty reduction is a complex systematic project that involves such disciplines as the economy, politics, culture, geography, society, and psychology, and changes with the changes in space, time, and developmental environment. China's sustainable poverty reduction is plagued not only by uncertain risks in the external environment, such as climate change and trade tensions, but also faces a series of challenges, such as the transformation of modes of economic development and the increasing constraints on resources and the environment. Thus, promoting research on poverty alleviation in development geography in China can provide a platform for multidisciplinary research that can be useful for practical measures.

\section{References}

Alkire S, 2002. Dimensions of human development. World Development, 30(2): 181-205.

Alkire S, Foster J, 2011. Counting and multidimensional poverty measurement. Journal of Public Economics, 95(7/8): 476-487.

Arn J, 1994. Marxism and the political economy of third world urban poverty. History of European Ideas, 19(1-3): $123-129$.

Charfeddine L, Kahia M, 2019. Impact of renewable energy consumption and financial development on $\mathrm{CO}_{2}$ emissions and economic growth in the MENA region: A panel vector autoregressive (PVAR) analysis. Renewable Energy, 139: 198-213.

Chen W, Liu W D, Ke W Q et al., 2018. Understanding spatial structures and organizational patterns of city networks in China: A highway passenger flow perspective. Journal of Geographical Sciences, 28(4): 477-494.

Dasgupta P, Mäler K G, 1995. Poverty, institutions, and the environmental resource-base. Handbook of Development Economics, 3: 2371-2463.

De Haan L, Zoomers A, 2003. Development geography at the crossroads of livelihood and globalisation. Tijdschrift voor Economische en Sociale Geografie, 94(3): 350-362.

Deng X Z, Jin G, He S J et al., 2020. Research progress and prospect on development geography. Acta Geographica Sinica, 75(2): 226-239. (in Chinese)

Ding J J, Wang Z, Liu Y H et al., 2020. Rural households' livelihood responses to industry-based poverty alleviation as a sustainable route out of poverty. Regional Sustainability, 1(1): 68-81.

Dong Y, Jin G, Deng X Z, 2020. Dynamic interactive effects of urban land-use efficiency, industrial transformation, and carbon emissions. Journal of Cleaner Production, 270: 122547.

Glassman J, Samatar A I, 1997. Development geography and the third-world state. Progress in Human Geography, 21(2): 164-198.

Guo B S, He D W, Zhao X D et al., 2020. Analysis on the spatiotemporal patterns and driving mechanisms of China's agricultural production efficiency from 2000 to 2015. Physics and Chemistry of the Earth, Parts A/B/C, 102909.

Guriev S, Vakulenko E, 2015. Breaking out of poverty traps: Internal migration and interregional convergence in Russia. Journal of Comparative Economics, 43(3): 633-649.

Harding D J, 2003. Counterfactual models of neighborhood effects: The effect of neighborhood poverty on dropping out and teenage pregnancy. American Journal of Sociology, 109(3): 676-719. 
Haushofer J, Fehr E, 2014. On the psychology of poverty. Science, 344(6186): 862-867.

Haveman R, Wolff E N, 2004. The concept and measurement of asset poverty: Levels, trends and composition for the US, 1983-2001. The Journal of Economic Inequality, 2(2): 145-169.

Hirschman A O, Lindblom C E, 1962. Economic development, research and development, policy making: Some converging views. Behavioral Science, 7(2): 211-222.

Jin G, Chen K, Wang P et al., 2019. Trade-offs in land-use competition and sustainable land development in the North China Plain. Technological Forecasting and Social Change, 141: 36-46.

Jin G, Deng X Z, Dong Y et al., 2020. China's multidimensional poverty measurement and its spatiotemporal interaction characteristics in the perspective of development geography. Acta Geographica Sinica, 75(8): 1633-1646. (in Chinese)

Jin G, Deng X Z, Zhao X D et al., 2018. Spatiotemporal patterns in urbanization efficiency within the Yangtze River Economic Belt between 2005 and 2014. Journal of Geographical Sciences, 28(8): 1113-1126.

Jin G, Guo B S, Deng X Z, 2020. Is there a decoupling relationship between $\mathrm{CO}_{2}$ emission reduction and poverty alleviation in China? Technological Forecasting and Social Change, 151: 119856.

Jin G, Shi X, He D W et al., 2020. Designing a spatial pattern to rebalance the orientation of development and protection in Wuhan. Journal of Geographical Sciences, 30(4): 569-582.

Kim R, Mohanty S K, Subramanian S V, 2016. Multilevel geographies of poverty in India. World Development, 87: 349-359.

Li X H, Zhou Y, Chen Y F, 2020. Theory and measurement of regional multidimensional poverty. Acta Geographica Sinica, 75(4): 753-768. (in Chinese)

Liao C, Fei D, 2019. Poverty reduction through photovoltaic-based development intervention in China: Potentials and constraints. World Development, 122: 1-10.

Liu X P, Li W H, Wang P et al., 2019. Local differentiation and alleviation of poverty in underdeveloped areas based on development geography. Acta Geographica Sinica, 74(10): 2108-2122. (in Chinese)

Liu Y S, Liu J L, Zhou Y, 2017. Spatio-temporal patterns of rural poverty in China and targeted poverty alleviation strategies. Journal of Rural Studies, 52: 66-75.

Liu Y S, Wang Y S, 2019. Rural land engineering and poverty alleviation: Lessons from typical regions in China. Journal of Geographical Sciences, 29(5): 643-657.

Liverman D M, 2018. Geographic perspectives on development goals: Constructive engagements and critical perspectives on the MDGs and the SDGs. Dialogues in Human Geography, 8(2): 168-185.

Love I, Zicchino L, 2006. Financial development and dynamic investment behavior: Evidence from panel VAR. The Quarterly Review of Economics and Finance, 46(2): 190-210.

Malerba D, 2020. Poverty alleviation and local environmental degradation: An empirical analysis in Colombia. World Development, 127: 104776.

Malik A, Temple J R, 2009. The geography of output volatility. Journal of Development Economics, 90(2): $163-178$.

Mawdsley E, 2017. Development geography 1: Cooperation, competition and convergence between 'North' and 'South'. Progress in Human Geography, 41(1): 108-117.

Merfeld J D, 2019. Spatially heterogeneous effects of a public works program. Journal of Development Economics, 136: 151-167.

Myrdal G, Sitohang P, 1957. Economic Theory and Under-developed Regions. London: Duckworth.

Nurkse R, 1952. Some international aspects of the problem of economic development. The American Economic Review, 42(2): 571-583. 
Ogutu S O, Qaim M, 2019. Commercialization of the small farm sector and multidimensional poverty. World Development, 114: 281-293.

Perroux F, 1950. Economic space: Theory and applications. The Quarterly Journal of Economics, 64(1): 89-104.

Ravallion M, Datt G, Van D W D, 1991. Quantifying absolute poverty in the developing world. Review of Income and Wealth, 37(4): 345-361.

Rawal N, 2008. Social inclusion and exclusion: A review. Dhaulagiri Journal of Sociology and Anthropology, 2: $161-180$.

Ren Q, Huang Q X, He C Y et al., 2018. The poverty dynamics in rural China during 2000-2014: A multi-scale analysis based on the poverty gap index. Journal of Geographical Sciences, 28(10): 1427-1443.

Rey S J, 2001. Spatial empirics for economic growth and convergence. Geographical Analysis, 33(3): $195-214$.

Rey S J, Murray A T, Anselin L, 2011. Visualizing regional income distribution dynamics. Letters in Spatial and Resource Sciences, 4(1): 81-90.

Rodríguez-Pose A, Hardy D, 2015. Addressing poverty and inequality in the rural economy from a global perspective. Applied Geography, 61: 11-23.

Saunders P, Naidoo Y, Griffiths M, 2008. Towards new indicators of disadvantage: deprivation and social exclusion in Australia. Australian Journal of Social Issues, 43(2): 175-194.

Sen A, 1976. Poverty: An ordinal approach to measurement. Econometrica: Journal of the Econometric Society, 44(2): 219-231.

Wang, Y H, Chen Y F, Chi Y et al., 2018. Village-level multidimensional poverty measurement in China: Where and how. Journal of Geographical Sciences, 28(10): 1444-1466.

Wu Y F, Feng W L, Zhou Y, 2019. Practice of barren hilly land consolidation and its impact: A typical case study from Fuping County, Hebei Province of China. Journal of Geographical Sciences, 29(5): 762-778.

Xu Y, Duan J, Xu X R, 2018. Comprehensive methods for measuring regional multidimensional development and their applications in China. Journal of Geographical Sciences, 28(8): 1182-1196.

Yang Y Y, de Sherbinin A, Liu Y S, 2020. China's poverty alleviation resettlement: Progress, problems and solutions. Habitat International, 98: 102135.

Zhang H M, Wu K, Qiu Y M et al., 2020. Solar photovoltaic interventions have reduced rural poverty in China. Nature Communications, 11(1): 1-10. 